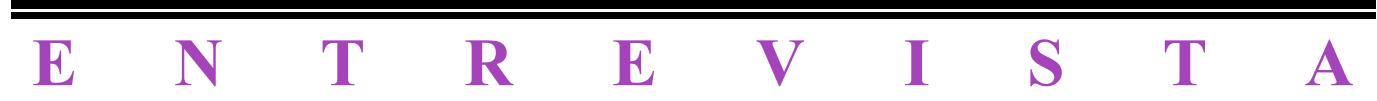




\section{ENTREVISTA \\ A ULRICH KLUG}

1.

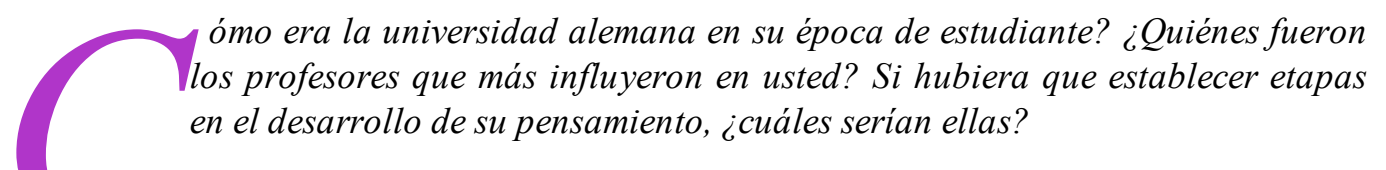

Estudié derecho y filosofía en la Universidad de Berlín. Cuando ingresé, en el semestre de invierno de 1933, los problemas de la vida universitaria eran graves. Entre los estudiantes había muchos nazis, aunque también un número no menor de opositores al dictador Hitler, que acababa de llegar al poder. La mayoría de los profesores no eran nazis militantes, pero sí conservadores -los llamados «alemanes nacionales»- que no habían prestado su apoyo a la República de Weimar y, por lo tanto, eran también responsables de la implantación del régimen nazi.

Sorprendentemente, había todavía profesores judíos en actividad, como Ernst Rabel, el famoso romanista, y Martin Wolff, el no menos conocido civilista.

Con ambos tuve contacto después de haber concluido mis estudios de derecho en octubre de 1936, como asistente y hasta la emigración de ambos poco antes del estallido de la Segunda Guerra Mundial (Wolff en 1937 y Rabel en 1938).

Pero ya muy pronto fueron designados profesores nazis, como Carl Schmitt y Reinhard Höhn (quien más tarde fuera general de la SS); ambos prestaron su criminal contribución intelectual al terror nacionalsocialista. Especial rechazo provocaron en mí las descaradamente antisemitas lecciones de Carl Schrnitt, a quien Hitler, en señal de agradecimiento, había nombrado consejero de Estado.

Sus reiteradas difamaciones de Hans Kelsen y de otros científicos judíos -provocadas por un notorio sentimiento de envidia y odio- carecían de todo fundamento 
medianamente discutible. A pesar de la tortura que significaba escuchar sus primitivos comentarios, desprovistos de toda espiritualidad, como estudiante no había más remedio que asistir a sus clases, ya que Schmitt integraba a menudo los tribunales de examen. En aquellos años, dispuso que, en la biblioteca del Seminario, los libros de Kelsen, al igual que los de otros autores judíos, llevaran en la tapa pegado como advertencia un círculo amarillo.

Como estudiante de derecho positivo, me impresionaron fuertemente las lecciones de Rabel y Wolff. A la filosofía del derecho me introdujeron las lecciones de Carl August Emge. Era el sucesor en la cátedra de Rudolf Stammler y procedía del campo de la tradición intelectual del neokantismo. Su Historia de la Filosofía del Derecho, publicada en 1931, fue la primera obra de filosofía del derecho que estudié. Su seminario, en el que conocí al joven Theodor Viehweg, era un verdadero oasis intelectual en la Universidad de Berlín, que día a día se volvía más nazi. Todavía hoy puede percibirse esto leyendo los aforismos que Emge publicara en 1942 bajo el título Aquende y allende la injusticia. Dedicó esta obra a Georg Christoph Lichtenberg. Su génesis está vinculada con las discusiones en los seminarios.

También tengo que agradecerle a Emge el interés por la investigación moderna de la lógica. No obstante no haber recorrido él mismo este camino, me señaló la importancia del «Círculo de Viena» y de la «logística». Así conocí las obras de Rudolf Carnap, Bertrand Russell, Alfred Tarski, Ludwig Wittgenstein, David Hilbert, Joseph M. Bochenski y Heinrich Scholz. Emge estimuló mi creciente interés por este campo de la filosofía y mi intento de aplicarlo a la filosofía del derecho. En 1938, conjuntamente con Eduard Kohlrausch, un penalista procedente de la tradición de Franz von Liszt, se puso a mi disposición para mis trámites de habilitación. En 1939, presenté ante la Facultad de Derecho de la Universidad de Berlín mi trabajo de habilitación Lógica jurídica, con los votos positivos de Emge y Kohlrauch. A pesar de este apoyo, mi trabajo fue rechazado por razones políticas. Sólo después de la guerra, en 1950, pude concluir mi habilitación, en Heidelberg, con el apoyo del ya entonces internacionalmente conocido filósofo del derecho Karl Engisch.

2. Su forma de entender la lógica jurídica constituyó una vía distinta, tanto en relación con la lógica deóntica como con las teorías de la argumentación, al estilo de la tópica de Viehweg o de la nueva retórica de Perelman. ¿Podría precisar en qué consiste la diferencia entre su enfoque y el de las teorías de la argumentación? 
¿Cuáles cree que han sido los principales logros de su concepción de la lógica jurídica en tanto lógica formal aplicada al derecho? ¿Qué opina sobre el auge que en los últimos tiempos ha adquirido el tema de la argumentación jurídica, tal como está presente en la obra de Aulis Aarnio, Robert Alexy, Neil MacCormick o Aleksander Peczenik, entre otros?

El enfoque de las teorías de la argumentación al estilo de la tópica de Viehweg o de la nueva retórica de Perelman se diferencia del de mis intentos en el ámbito de la lógica jurídica por lo que respecta a la ordenación de diferentes grados de análisis de las tesis jurídicas y en sus fundamentaciones. Esto puede demostrarse con el modelo de la fundamentación jurídica axiomática y cuasi axiomática:

De toda fundamentación de un fallo judicial se exige «coherencia», es decir, coherencia lógica. Si en la fundamentación de un fallo se descubre una falacia, por ejemplo, una demostración circular (circulus in probando, petitio principii), entonces, según el Derecho procesal alemán, procede la revisión de la sentencia.

En el escrito de revisión se aduce la «violación de leyes del pensamiento». En tales casos se presupone la aplicabilidad del método axiomático, tanto en la estructura formalizada como en la no formalizada, del lenguaje ordinario. Se examina siempre si de las premisas correspondientes -los presupuestos del derecho legislado o consuetudinario- se infiere coherentemente la decisión del tribunal. Un fallo judicial opera con conclusiones a partir de presupuestos; es, por lo tanto, en cada caso, un sistema axiomático que -recurriendo a un ordenador- puede ser formalizado y que -si se utiliza el lenguaje ordinario- contiene un sistema cuasi axiomático. Pero también en el caso de esta última estructura nos encontramos con un sistema cerrado de derivación, con las premisas dadas de antemano por la ley y a las que he propuesto llamarlas cuasi axiomas porque no están exactamente formalizadas con la ayuda de un cálculo lógico. Pero esto no cambia en nada el hecho de que las conclusiones formuladas en el lenguaje ordinario pueden ser examinadas por lo que respecta a su precisión lógica y mostrarse la existencia de errores lógicos. La clásica silogística aristotélica resulta ser aquí un instrumento perfectamente utilizable. Esta es la perspectiva de la lógica jurídica.

Las teorías de la argumentación al estilo de la tópica de Viehweg o de la nueva retórica de Perelman tienen una función no menos importante. Son métodos que pueden ser utilizados adecuadamente en una grada previa del análisis, es decir, en la 
búsqueda de los axiomas (premisas). En esta medida, han logrado un interesante progreso científico en la teoría jurídica. Pero la exacta subsunción lógica -debido a la necesidad de coherencia en la fundamentación de la decisión judicial- sigue siendo irrenunciable, a menos que se quiera renunciar a la seguridad jurídica, es decir, a uno de los fundamentos del Estado de derecho.

Como es sabido, también Alexy parte de las dos gradas de análisis y distingue entre la derivación lógica de la sentencia judicial a partir de las premisas presupuestas en la fundamentación (justificación interna) y la averiguación de las premisas (justificación externa).

Me parece que algo similar vale para las tesis analíticas de Aarnio, MacCormick y Peczenik, que han proporcionado importantes impulsos y sugerencias para el desarrollo de la teoría jurídica, pero cuyo análisis superaría los límites de esta entrevista.

3. Usted publicó su muy conocido libro Lógica jurídica en 1951, es decir, en el mismo año en que apareció el famoso artículo de Georg Henrik von Wright «Deontic logic», que suele ser considerado como el origen de la lógica deóntica. ¿Podría precisar el alcance de sus tesis? ¿Cómo valora el desarrollo de la lógica deóntica?

Como he dicho, ya en 1939 estaba lista la primera versión de la Lógica jurídica. Cuando entró en prensa, en 1950 y apareció la primera edición, en 1951, todavía no conocía la investigación para mí extraordinariamente sugestiva «Deontic Logic» de Georg Henrik von Wright, publicada en 1951 en la revista Mind. En la segunda edición de la Lógica jurídica, publicada en 1958, pude ya referirme a este trabajo. Llegué entonces a la conclusión de que para la formalización de enunciados acerca de formas de comportamiento permitidas o prohibidas, tales como se dan dentro del marco de las estructuras lógicas de los enunciados proposiciones jurídicos en las leyes de un ordenamiento jurídico, un cálculo deóntico era quizás posible pero no necesario para la lógica jurídica. En la cuarta edición de la Lógica jurídica, publicada en 1982, analicé más de cerca la importancia de los cálculos de la lógica deóntica para la presentación, análisis y examen lógicos de las conclusiones jurídicas. Aquí presupuse que -de acuerdo con el uso ordinario del lenguaje alemán- las disposiciones legales acordadas por el legislador -el Parlamento- y publicadas en el Boletín Oficial pertenecen a la clase de las normas. Ello responde a una convención semántica de los juristas en el ámbito de lengua alemana. La discusión de estas normas en 
los comentarios y tratados jurídicos se lleva a cabo como un discurso sobre normas en un metanivel semántico.

En la Lógica jurídica, mis esfuerzos se centran en el desarrollo de primeros puntos de partida para métodos lógicos con los cuales ha de ser posible examinar la corrección lógica (no contradicción, independencia, completitud y decibilidad) de sistemas normativos (leyes, disposiciones legales particulares, etc.). Aquí pensé también ya en trabajos analíticos previos para las decisiones judiciales con la ayuda de la informática. El hecho de que sólo pudiera tratarse de comienzos está vinculado con la dificultad de la utilización de ordenadores para la obtención de decisiones jurídicas, a pesar de que ya existen algunos éxitos en la praxis de la aplicación de las leyes (cfr. al respecto Herbert Fiedler, Thomas Barthel y Gerhard Voogd, Untersuchungen zur Formalisisierung im Recht als Beitrag zur Grundlagenforschung juristischer Datenverarbeitung [UFORED] Opladen, 1984).

En este contexto, me parece que hasta ahora la aplicación de los cálculos de la lógica deóntica no ha tenido éxito, por más interesantes que ellos sean desde el punto de vista científico, sobre todo desde la perspectiva de la teoría jurídica. Habrá que observar atentamente si nuevos desarrollos de las teorías de la lógica deóntica abren nuevas posibilidades, especialmente desde puntos de vista pragmáticos.

4. Eugenio Bulygin, en la página 22 de su Estudio preliminar a Normas jurídicas y análisis lógico(Madrid, 1988), libro en el que se publica la correspondencia que usted mantuviera con Hans Kelsen entre 1959 y 1965 sobre las relaciones lógicas entre las normas en general y las jurídicas en especial, le reprocha no admitir la necesidad de una lógica específica de las normas. Esto traería como consecuencia «una confusión inadmisible de dos niveles del lenguaje»: el de las normas y el de las proposiciones normativas. ¿Considera usted válida la objeción de Bulygin?

Esta crítica de Eugenio Bulygin es una de las contribuciones más importantes a la discusión de las tesis sobre el análisis de las normas que sostuviera en mi intercambio epistolar con Kelsen. Desde la perspectiva actual, coincido en muchos puntos con Bulygin. Por ello es deseable una continuación de la discusión.

Especialmente importante me parece el hecho de que es necesario indicar más claramente, en mis intentos de análisis, cuándo se trata de un análisis semántico y cuándo de uno sintáctico. Naturalmente, esto requiere una exposición más exacta. Aquí deseo referirme sólo a los siguientes puntos de discusión: 
a) Por lo pronto, conviene reflexionar sobre el aspecto sintáctico. Como se sabe, por sintaxis de un lenguaje se entiende la estructura de las oraciones derivables, formalmente correctas, determinada a través de las reglas de un lenguaje, sin hacer referencia a su significado (la semántica). De enunciados de normas ya dados -es decir, no de enunciados acerca de normas- es posible, por lo pronto, obtener sintácticamente otros enunciados. Así se procede, por ejemplo, en los lenguajes programados de la informática. Tal como lo ponen de manifiesto las aplicaciones prácticas de la informática hasta ahora realizadas, en el caso de las normas no resultan dificultades sintácticas insuperables para llegar a conclusiones normativas y, de esta manera, someter a prueba la coherencia de un sistema normativo dado. Así, por ejemplo, con respecto al derecho penal de la República Federal de Alemania puede comprobarse -sin que para ello sea necesario recurrir a interpretaciones deónticas o de algún otro tipo del contenido de significado- que las normas del $\S 211$, párrafo 1 («El asesinato será castigado con prisión perpetua») y el $\S 212$, párrafo 1 («Quien mate a una persona, sin ser asesino, será castigado con prisión no inferior a cinco años») no se contradicen.

b) Tanto desde el punto de vista sintáctico como semántico, es necesaria una separación exacta y claramente reconocible de los niveles del lenguaje, tal como lo exige Bulygin, ya que en el análisis de sistemas de enunciados no pocas veces hay que considerar estructuras de varios niveles. Así, por ejemplo, cuando en un trabajo jurídico se estudia una sentencia judicial, estamos por lo general, frente a tres niveles lingüísticos. El primero -la base- es la norma; el segundo, es el del grupo de enunciados interpretativos de la fundamentación de la sentencia; y en el tercer nivel lingüístico nos encontramos con las consideraciones valorativas de la sentencia judicial. Por lo tanto, los enunciados que figuran en el trabajo jurídico son miembros de un meta-meta-lenguaje. Desde luego, el que en esta estructura haya que presuponer diferencias sintácticas, es algo que todavía merece reflexión y discusión.

5. En su trabajo «El derecho de resistencia como derecho humano universal», incluido en su libro Problemas de la filosofía y la pragmática del derecho (Barcelona, 1989), insiste en la importancia de los principios jurídicos suprapositivos de valor hipotético y sostiene una posición de neutralidad valorativa. En la página 51 del mencionado libro afirma: "Partiendo de esta actitud filosófico-jurídica básica y abierta, no se encuentran vinculaciones 
con opiniones filosóficas, religiosas o ideológicas ni en la Carta de las Naciones Unidas de 1945, ni en la Declaración Universal de Derechos Humanos de 1948...» ¿Piensa usted que esta Declaración está aislada del proceso histórico de la Ilustración o de la experiencia con la dictadura nazi? Y si tal no es el caso, ¿no es entonces esta Declaración justamente la expresión de una actitud filosófica y de una ideología política determinadas?

Efectivamente, la Declaración de los Derecho Humanos de 1948, al igual que la Carta de las Naciones Unidas de 1945 -a las que habría que agregar los dos pactos de derechos humanos de 1966- tienen que ser vistas en el proceso histórico como vinculadas con la Ilustración, por una parte, y con las experiencias de la dictadura nazi, por otra. La referencia a la apertura filosófico-jurídica ha de ser vista como vinculada a los mismos factores. Con esto se hace referencia a la pluralidad esclarecida, de acuerdo con la cual los derechos humanos no dependen de ningún presupuesto filosófico, religioso o ideológico. Por lo tanto, debe estar prohibida la exclusión del goce de los derechos humanos a los «infieles», a los «enemigos ideológicos», «adversarios filosóficos»u otros «disidentes». Con esto se quiere indicar, sobre todo, el rechazo de premisas irracionales y la aceptación de la estructura hipotética de las suposiciones básicas, tal como lo subrayara la Ilustración. En cambio, no queda excluida la profesión subjetiva de fe en la humanidad, en el sentido más amplio de la palabra. En esta medida, la fundamentación jurídica mundial y la incorporación en el derecho internacional de los derechos humanos son expresiones de una actitud filosófica y de una ideología política, a la vez que una implicación de la Ilustración y de la experiencia con la dictadura nazi.

6. A lo largo de toda su vida, ha puesto usted de manifiesto su rechazo de las dictaduras y su vocación democrática. La República Federal de Alemania acaba de cumplir cuarenta años de existencia. ¿Piensa usted que en estas cuatro décadas su país ha mantenido un desarrollo lineal de afianzamiento de la democracia o considera que se produjeron fisuras que, en algún momento, significaron una amenaza para el ordenamiento democrático en libertad? La reforma de la Ley Fundamental de 1968 y la inclusión de disposiciones sobre el estado de excepción, ¿no constituiría una de estas fisuras?

En el desarrollo de la República Federal de Alemania ha 
habido, en mi opinión, realmente fisuras que perjudicaron el fortalecimiento continuado de la todavía relativamente joven democracia y que constituyeron una amenaza para el orden básico de democracia en libertad. Sin embargo, antes de entrar a considerar este proceso, quisiera señalar algunos «defectos de nacimiento», que se produjeron al entrar en vigencia la Ley Fundamental en 1949.

Ya del patético Preámbulo resulta una carga ideológica irracional y problemática con previsibles posibilidades de interpretación nacionalista. Este preámbulo reza:

«Consciente de la responsabilidad ante Dios y los hombres, animado de la voluntad de defender su unidad nacional y política y de servir a la paz del mundo, integrado en una Europa unida sobre la base de la igualdad de derechos, el pueblo alemán de los Estados federados de Baden, Baviera, Bremen, Hamburgo, Hesse, Baja Sajonia, Renania del Norte-Westfalia, Renania-Palatinado, Schleswig-Holstein, Wurtemberg-Baden y Wurtemberg-Hohenzollern, con el propósito de dar un nuevo ordenamiento a la vida política durante un período de transición, en virtud de su poder constituyente, ha acordado la presente Ley Fundamental de la República Federal de Alemania, actuando también en nombre de aquellos alemanes a quienes estaba vedada la colaboración, y manteniendo en pie la invitación para que todo el pueblo alemán, en libre autodeterminación, consume la unidad y libertad de Alemania.» (Subrayado de U. K.)

Se podría haber ahorrado el Preámbulo. La Constitución de la Paulskirche de Francfort, del año 1849, que desgraciadamente fracasara como proyecto democrático porque en la Alemania dividida en pequeños Estados monárquicos no fue posible imponer la democracia, no incluía ningún preámbulo. El de la Constitución de Weimar del año 1919 era breve y relativamente concreto:

«El pueblo alemán, unido en sus diferentes etnias y animado del deseo de renovar y afianzar su Estado en libertad y justicia, servir la paz interna y externa y promover el desarrollo social, ha acordado la presente Constitución.»

Hubiera sido más inteligente atenerse, por lo menos, al modelo de Weimar. Se hubieran evitado así muchas polémicas ideológicas como la vinculada con el mandato de reunificación de la República Federal de Alemania con la RDA.

Un error fue también incluir la prohibición de la pena de muerte en el artículo 102, en la Sección VIII a de la Ley Fundamental, 
dentro del marco de la regulación de las «tareas de la comunidad». Debido a la gran importancia de esta prohibición y teniendo en cuenta su -en mi opinión- indiscutible carácter de derecho fundamental, hubiera sido más correcto incluirla en la Sección 1 de la Ley Fundamental a fin de que, en caso de una discusión acerca de una eventual reunificación, la pena de muerte quedara expresamente excluida de la misma.

Finalmente, fue también un «error inicial» no distanciarse más claramente, con formulaciones adecuadas, del pasado nacionalsocialista. Como consecuencia de ello, se acumulan fatales continuidades, tanto en lo material como en lo personal, en la administración pública y en la justicia. Así pudo suceder, entre otras cosas, que de los «jueces» del «Tribunal del Pueblo»-aquel instrumento del terror nazi, que impusiera ilegalmente más de 5.000 penas de muerte- ni uno sólo fuera sometido a proceso penal y condenado en la posguerra.

Efectivamente, la reforma de la Ley Fundamental a través de la legislación sobre el estado de excepción en 1968 constituyó también una fisura. En ese año, se reformó la Ley Fundamental en un punto esencial. Hasta ese momento existía una garantía general de la vía judicial, ya que en el artículo 19 de la Ley Fundamental se decía desde 1949 hasta 1968: «Toda persona cuyos derechos sean vulnerados por el poder público podrá recurrir a la vía judicial.» Es decir, cualquiera podía recurrir ante los tribunales cuando se sintiera lesionado en sus derechos. Hasta 1968 no existía ninguna limitación a la posibilidad de defenderse frente al Ejecutivo a través del Poder Judicial. Este era un principio de gran importancia desde el punto de vista del Estado de derecho y de la democracia. Lamentablemente, en 1968 este principio fue lesionado y limitado en el sentido de que la garantía de la vía judicial quedaba eliminada por medidas que se realicen como control de la correspondencia postal y de las telecomunicaciones y que, como se dice en el artículo 10 -al cual remite ahora el artículo 19-, «tengan como fin proteger el régimen fundamental de libertad y la democracia o la existencia o seguridad de la Federación o de un Estado federado». De esta manera se confiere a los servicios secretos métodos de espionaje y de vigilancia contrarios al Estado de derecho, ya que queda excluido el control posterior por parte de los tribunales.

Otra quiebra en el desarrollo de la República Federal de Alemania para el afianzamiento de la democracia fue la reforma de la Ley Fundamental con el objeto de posibilitar la creación de tribunales penales militares para los miembros de las Fuerzas Armadas. A pesar de que la jurisdicción penal militar fue permitida 
sólo para el «caso de defensa», ya poco después de la reforma de la Ley Fundamental, en el Ministerio Federal de Justicia «se habían realizado amplios trabajos previos para la introducción de una jurisdicción penal militar», tal como se dijo por parte del Ministerio Federal de Justicia en una interpelación parlamentaria en 1984. Sólo a raíz de una fuerte crítica en la opinión pública parece que se dieron por terminados estos «trabajos previos». Pero, al mismo tiempo, no se modificó para nada la macabra situación jurídica en la Ley Fundamental. En verdad, el 40 aniversario de la República Federal de Alemania hubiera sido una buena oportunidad para la eliminación de éste y de los otros puntos oscuros aquí mencionados. Pero para ello faltan los presupuestos políticos.

7. En reiteradas oportunidades usted ha señalado la ineficacia de los tribunales de la República Federal de Alemania para castigar a jueces y juristas que jugaron un papel decisivo en la implantación del régimen nazi. Por otra parte, usted es defensor incondicionado de un derecho penal «humano», opuesto desde luego a la pena de muerte y también a la imposición de la prisión perpetua. ¿Considera usted que debió haberse procesado a todos los culpables principales de la barbarie nazi y, en su caso, cuál debería haber sido la pena que en justicia merecían?

También dentro del marco de un derecho penal humano existe la obligación de someter a juicio y condenar no sólo a unos cuantos, sino a todos los culpables principales de la barbarie nazi. Una privación de la libertad de largos años, conjuntamente con un trabajo de reparación en beneficio de las víctimas del nazismo y sus deudos, hubiera sido la correcta medida de resocialización; y quizás en algunos casos particulares con aspectos especialmente humanos, podría haberse pensado excepcionalmente en indultos, con reducción condicional de la pena y adecuadas medidas de reparación para las víctimas.

8. Uno de los temas ético-jurídicos más discutidos en la actualidad es el vinculado con la prohibición de la producción y comercialización de las drogas. Como es sabido, existe, por una parte, una fuerte corriente de opinión que aboga por la despenalización de estas actividades; por otra, los gobiernos de los países afectados propician más bien una política jurídico-penal que tiende a reforzar las medidas de control con miras a la erradicación total del consumo de drogas. ¿Cuál de estas dos posiciones considera usted más adecuada desde el punto de vista ético-penal? 
Actualmente la problemática de las drogas es uno de los ámbitos más difíciles de la ética jurídico-penal. Pero me faltan los conocimientos necesarios para poder dar una respuesta no superficial a esta grave cuestión. Puedo sí señalar sin reservas que, en principio, la aplicación del derecho penal sólo puede ser considerada como medida de ultima ratio, ya que las normas del derecho penal son poco sensibles. 